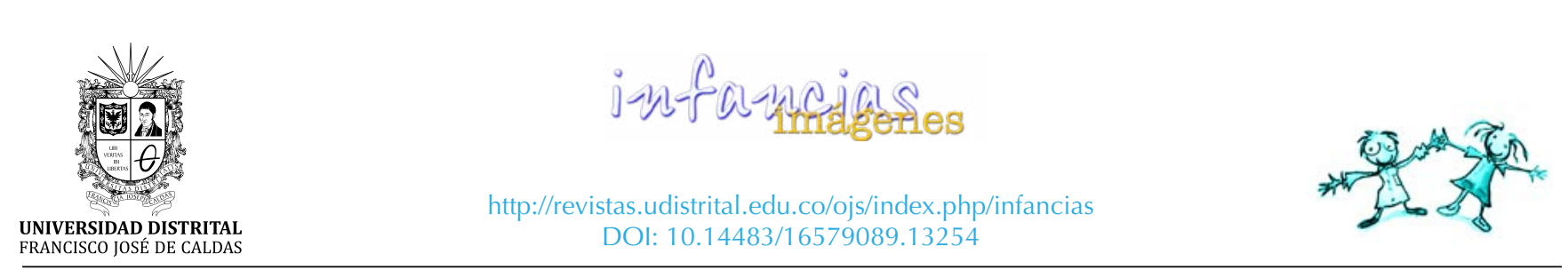

TEXTOS Y CONTEXTOS

\title{
La dilución de las asignaturas escolares en el preescolar público bogotano (1990-2000)*
}

\section{The dilution of school subjects in Bogota's public pre-school (1990-2000)}

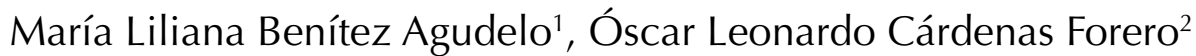

Para citar este artículo: Benítez, M. L.; Cárdenas, Ó. L. (2018). La dilución de las asignaturas escolares en el preescolar público bogotano (1990-2000). Infancias Imágenes, 18(1), 68-79

\section{Resumen}

El presente artículo de reflexión es una apuesta por describir las condiciones de existencia que se conjugaron durante la década de 1990 para iniciar la dilución de ciertos saberes escolares, a modo de asignaturas académicas; el florecimiento y fortalecimiento de otros, como estrategia de poder incluida para adelantar los procesos de preescolarización y la enseñanza de niños y niñas en el preescolar público bogotano. Lo anterior, desde el enfoque cualitativo, método arqueo-genealógico, apoyado en la analítica de la gubernamentalidad. A través de estas exploraciones se busca no solo mostrar el carácter histórico, fluctuante, móvil y mutable de los saberes escolares sino enriquecer el campo conceptual de la Historia de los Saberes Escolares. Para lograr este objetivo, se recurrió a la identificación en archivos de la época de los enunciados y regularidades que permitieron visibilizar objeto de estudio, juegos de acciones sobre acciones, tensiones, poderes y conflictos suscitados. Palabras clave: educación preescolar, escuela pública, aprendizaje, saberes escolares, dilución.
Recibido: 22-abril-2018 / Aprobado: 05-febrero-2019

\begin{abstract}
This paper of reflection is a commitment to describe the conditions of existence that were conjugated during the decade of 1990 to begin the dilution of certain school knowledge, as academic subjects; flourishing and strengthening of others, as a power strategy included to advance pre-schooling processes and the teaching of children in Bogota's public preschool. The previous, from a qualitative approach, arche-genealogical method, supported in the analytics of governmentality. Through these explorations we seek not only to show the historical, fluctuating, mobile and mutable character of school knowledge but to also enrich the conceptual field of the History of School Knowledge. In order to achieve this goal, archives of the historical period of statements and regularities were identified, which allowed the visualization of the objects of study, games of action through action, tensions, powers and caused conflicts.
\end{abstract}

Keywords: early childhood education, public education, learning, school knowledge, dilution.

Este artículo de reflexión es una derivación de las exploraciones y análisis adelantados en el marco de los encuentros realizados en el grupo de investigación Historia de las Disciplinas Escolares y en el semillero de investigación Historia de los Saberes Escolares en el Preescolar, adscritos a la Universidad del Tolima, en los que se indaga alrededor del estudio de los saberes escolares en la historia de la educación y la pedagogía colombiana. Dicho artículo se acopla, del mismo modo, a las reflexiones y hallazgos encontrados en el contexto del proyecto de investigación "Historia de los saberes escolares en el preescolar público bogotano de la década de los 90", actualmente en proceso de realización.

1 Licenciada en Ciencias Sociales; Especialista en Gerencia de Instituciones Educativas; Especialista en Pedagogía de la Recreación Ecológica. Docente del Colegio Instituto Técnico Industrial Piloto IED (Colombia). Correo electrónico: tomalibea@gmail.com

2 Licenciado en Ciencias Sociales; Especialista en Gerencia de Instituciones Educativas; Magíster en Desarrollo Educativo y Social. Profesor de la Universidad del Tolima. Grupo de investigación Historia de las Disciplinas Escolares, Universidad del Tolima. Correo electrónico: osle1972@gmail.comy olcardenasf@ut.edu.co 


\section{Proemio}

El estudio de los saberes escolares se ha ido constituyendo hoy en un campo importante de exploración pedagógica, educativa e histórica enriquecido por las investigaciones realizadas en el exterior por Chervel (1991), Goodson (1991) Viñao (2006), Cuesta (1997), y por Zuluaga (2003), Martínez (2015), Marín (2015), Ríos (2015), Álvarez (2015), entre otros, para el caso del país, todas ellas centradas "[...] en el estudio histórico de los contenidos de la enseñanza primaria y secundaria, de sus dinámicas internas y de las particularidades de lo que los niños y jóvenes aprenden en la escuela" (Álvarez y Taborda, 2014, p. 166). Gracias a la excavación de sus terrenos, ha sido posible dilucidar las formas particulares de cómo en el tiempo se han concebido, organizado e instalado, entre otros aspectos, las asignaturas académicas en la escuela como modos singulares adoptados por la enseñanza para impulsar los procesos de formación, gobierno y regulación de los niños, niñas y jóvenes, así como, sus trasmutaciones, permanencias y desvanecimientos.

Pero, además, se ha logrado comprender el saber escolar, siguiendo a Álvarez (2015), como una categoría en proceso de construcción, relacionada con aquello de lo que los maestros "[...] son capaces de hacer, de pensar, de proponer y de enseñar, cómo lo hacen, y cuál sería el estatuto y la naturaleza de ese saber" (p. 24), por esto, con base en lo expuesto por Ríos, "los saberes y disciplinas escolares poseen una autonomía constitutiva y son, en consecuencia, una invención de las prácticas de enseñanza" (2015, p. 11).

Del mismo modo, las pesquisas realizadas han posibilitado reconocer el carácter que la escuela y el maestro han asumido en diferentes y determinadas épocas, los contenidos culturales que se han incluido en los planes curriculares para enseñar, las didácticas establecidas; así como también los modelos específicos de sujetos los escolares que se quieren constituir y el tipo de sociedad que se desea establecer.

A pesar de su importancia, los estudios sobre los saberes escolares en el nivel educativo preescolar se encuentran aún en un proceso de germinación, lo que lo configura en un escenario emergente, en un espacio por explorar, en el que investigaciones orientadas a rastrear el origen, función y funcionamiento de los saberes escolares en la historia de la educación y la pedagogía se hacen pertinentes y fundamentales en el camino de crear y consolidar un campo de investigación de los saberes escolares en el preescolar.

Justamente entre estos estudios que se han gestado aparece el trabajo La historia de los saberes en el preescolar de la escuela pública bogotana (19801990), de 2018, una exploración histórica producida por el semillero de investigación Historia de los saberes escolares en el preescolar, auspiciado por la Universidad del Tolima y acoplado al grupo de investigación Historia de las disciplinas escolares. Este se orienta a examinar las condiciones de posibilidad (en términos de la procedencia, función y funcionamiento) que impulsaron la incursión de determinados saberes escolares en el preescolar público durante el decenio de 1980. Este último momento es crucial puesto que no solo se enunció la aparición del preescolar como un nivel educativo preliminar acoplado a la escuela primaria pública para preparar a los niños y niñas a los retos escolares posteriores, sino en el que se introdujo como estrategia preescolarizante la inclusión de saberes escolares a modo de asignaturas de enseñanza articuladas a las áreas de conocimiento, con las que se pretendió el desarrollo y la formación infantil.

Entre estas materias escolares se encontraban entonces: las Ciencias Naturales y de la Salud, Prematemáticas, Ciencias Sociales, Educación Artística, Pre-lecto-escritura, Religión, entre otras. "A partir de las que se condensarían las temáticas y aspectos a considerar en las prácticas en el aula, cada una de las cuales de modo fragmentado posibilitaron los procesos de enseñanza escolar" (Cárdenas et al., 2018, p. 40); muchas de ellas:

[...] creaciones o adaptaciones de los maestros o efecto del fenómeno de primarización, según el cual ciertos contenidos abordados en la educación primaria se acondicionaban para el trabajo con los niños preescolares, con lo que se quiso legitimar una manera particular de ser de este nivel educativo, es decir, como un instante preliminar y de preparación para la escuela primaria. (Cárdenas et al., 2018, p. 12) 
Así las cosas, como una manera de enriquecer este campo de exploración de los saberes en el preescolar que se vienen constituyendo, de apoyar y complementar trabajos como el anteriormente enunciado, pero también, del campo de estudio de la infancia en el país, se plantea el presente estudio como una apuesta de carácter histórico que busca develar las condiciones que posibilitaron durante la década de los 90 la dilución de las materias de enseñanza, herencia de los años 80, de los planes curriculares para el caso del preescolar público bogotano.

Con ello, visibilizar la instalación de nuevas formas de ser y proceder de la enseñanza, circunstancias que reconfiguraron las prácticas de las maestras y maestros en el aula, así como, la conversión del carácter y concepción del preescolar público, y por supuesto, de la infancia escolarizada.

Y en esta perspectiva, contribuir en la validación y reconocimiento de los saberes escolares como componentes de "un espacio más amplio y abierto de un conocimiento" (Zuluaga, 2003, p. 17), como construcciones históricas y fluctuaciones temporales, acopladas a la racionalidad de cada época, como estrategia complementaria de los procesos de aprestamiento escolar, de desarrollo infantil y de regulación de las conductas infantiles; los cuales, paulatinamente, efecto de la convergencia de múltiples prácticas, se fueron desvaneciendo o trasmutando del andamiaje curricular instituido para posibilitar la instauración de estados distintos de la enseñanza.

Conforme con esto, trabajos con esta perspectiva permiten no solo mostrar el carácter cambiable de los saberes escolares, de lo que permanece, se trasforma o diluye en el tiempo en relación con sus contenidos de enseñanza, además admiten colocar en un lugar privilegiado la pregunta por lo que se enseña a los niños y niñas en el preescolar, en específico, el preescolar público bogotano. Un cuestionamiento que hoy se hace difuso en las formulaciones de las políticas educativas relacionadas, precisamente, con la enseñanza preescolar. En consecuencia, más allá de preguntarse por aquello que se enseña en el preescolar, entre otros aspectos, las apuestas de atención a la infancia preescolarizada se han dirigido en los últimos años a afrontar las discusiones sobre el sentido de este nivel educativo, revelando la tensión actual "[...] entre el asistencialismo y el desarrollo integral de los niños y la disposición para enfrentar la escuela primaria" (Cárdenas et al., 2018, p. 13).

Reflexionar, entonces, por aquello que se enseña en la escuela preescolar implica problematizar su sentido y significado, su carácter, esencia, función y el estado que asume en determinados momentos para apoyar los procesos educativos de la infancia. Es decir, preguntarse por las acciones que motivaron su invención, su establecimiento y permanencia en el tiempo, por las materias escolares que se introdujeron para enseñar, como también por las que se disolvieron, permanecieron o se alteraron para adelantar los procesos de formación infantil, de aprestamiento y preescolarización. Y, como resultado de ello, en esas exploraciones mostrar los juegos de poder, intereses y conflictos que se suscitaron para legitimar ciertos saberes escolares e invalidar otros conforme a la racionalidad de cada época, a la sociedad que se pretendía establecer y al sujeto preescolar que se requería constituir para integrarlo a ese modelo social.

Del mismo modo, al referirse la pregunta por los saberes escolares, por los contenidos de enseñanza que se instalan, por las materias escolares que se aprueban (pero también por las que se disuelven y censuran), acarrea a despojarlas de su condición de verdad, desnaturalizar su existencia, preguntar su legitimidad y determinar si fueron creaciones asociadas a la necesidad de desarrollar el conocimiento de los niños y niñas o para permitir su asistencia, cuidado, desarrollo y crecimiento, o quizás, un efecto del progreso social, de la evolución humana, de la promulgación de una norma, o por el contrario, variaciones que florecieron en el tiempo como condiciones históricas, fluctuantes, mutables, resultado de la conjunción de múltiples prácticas y de juegos de acciones sobre acciones, para constituir de un modo distinto la escuela preescolar, sus maestros y maestras, así como a los niños y niñas, conforme a la racionalidad establecida en el momento. 


\section{La metodología}

Para adelantar las pesquisas, el presente trabajo tiene un enfoque cualitativo, con un método arqueo-genealógico apoyado en las formulaciones de la analítica de la gubernamentalidad expresadas por Michel Foucault en sus investigaciones. De modo preliminar, se recurrió a la exploración del archivo documental de la época constituido por una multiplicidad de fuentes primarias, como documentos normativos, textos escolares y entrevistas a los maestros y maestras de entonces, entre otros. En estos, se buscaron los indicios que permitieran dar cuenta de las condiciones de existencia que en determinado momento confluyeron para impulsar la evanescencia de ciertas disciplinas escolares del preescolar público bogotano y, con ellas, un modo singular de ser de la enseñanza.

A través de cada uno de ellos, se intentó recoger los testimonios de la época para construir el diagrama de la escuela preescolar en la década de los 90 (y compararla con la escuela de los 80), en relación con la enseñanza y sus contenidos escolares, con las materias escolares que permanecían instaladas y aquellas que, por efecto de la conjunción de múltiples condiciones, acopladas a la racionalidad del momento, se trasfiguraron o desaparecieron. Dicho ejercicio investigativo permitió identificar aquellos contenidos de enseñanza que emergieron durante ese tiempo, así como también aquellos que se conservaron dentro de los planes curriculares y los que en definitiva se desvanecieron para posibilitar nuevas maneras de ser del enseñar.

Por tanto, adoptar una perspectiva arqueo-genealógica significa recocer al investigador como un arqueólogo que recurre a una caja de herramientas para excavar en los expedientes de la época, aquellos vestigios y huellas que se han establecido y considerado como verdades que legitiman la incursión, cambio o dilución de los saberes escolares en el preescolar, que dirigen y regulan las prácticas, didácticas y discursos de ese momento histórico en el que se consideró necesario incorporarlos en este nivel educativo como una acción encaminada a la regulación y formación infantil.

En ese camino, el arqueólogo se sumerge en el archivo y escarba en las fuentes primarias el conjunto de enunciados ("eso que se murmura") que en la década de los 90 aparecían institucionalizados, para extraerlos, mostrarlos, desnaturalizarlos y problematizarlos, evidenciando su carácter mutable y los múltiples rostros que asumen en el tiempo para regular la enseñanza.

Adicional al papel del arqueólogo que escudriña en el pasado las marcas que se instalan para orientar las actuaciones y la racionalidad de cada época, el investigador se cubre con el ropaje del geneálogo, como lo sostiene Foucault (1983), una investidura que le permite identificar las diversas formas que adopta el poder en ese tiempo, que actuando convergentemente impulsó la instalación de los saberes escolares en la forma de construcciones históricas susceptibles de modificarse. Por tanto:

Se trata de develar las políticas de verdad, los intereses existentes y sus formas hegemónicas, los juegos de las acciones, en fin, de describir las condiciones de emergencia que en cierto momento operan en la racionalidad que caracteriza a una sociedad en un momento dado. (Cárdenas et. al., 2018, p. 86)

Así, mientras la exploración arqueológica posibilita identificar los saberes escolares como efectos y objetivaciones de la década de los 90 en el preescolar, el rastreo genealógico permite "la descripción de las condiciones de existencia, los juegos del poder, las prácticas institucionalizadas, las estrategias y las condiciones históricas en las que aparecieron dichas objetivaciones" (Cárdenas et. al., 2018, p. 87).

El trabajo de investigación comenzó con un proceso de revisión y selección de las fuentes primarias y secundarias. Posteriormente, se consignó en las fichas de recolección de información aquellos datos que permitieron elaborar el diagrama de la escuela preescolar en relación con la procedencia, función y funcionamiento de los saberes escolares en el decenio de los 90, explorando aquello que se conservó, trasformó o diluyó en comparación con lo que aparecía instalado en la década anterior.

Una vez se identificaron los enunciados en las fichas de recolección de la información, se procedió a agruparlos en familias, determinando regularidades, para luego apostar por la construcción de los espacios denominados por Deleuze (1987) 
como correlativo, colateral y complementario, a través de los cuales fue posible determinar las condiciones de existencia que, actuando acopladas a la racionalidad de los 90, impulsaron la dilución de ciertos saberes escolares del preescolar público bogotano.

\section{La racionalidad educativa entre los años 80 y los 90}

En el decenio de 1980, obedeciendo a una racionalidad educativa singular ${ }^{3}$, se instalaron en el preescolar público ofrecido por el Estado un conjunto de saberes escolares, a modo de materias de enseñanza publicados en el documento del Ministerio de Educación Nacional (MEN) "Currículo de Preescolar" (1984). En este, se pretendió no solo complementar las estrategias de preescolarización de la época sino la regulación y el encauzamiento de los comportamientos, actitudes y valores de los niños y niñas entre los 5 y 6 años a los requerimientos sociales de entonces, e iniciar con ello sus procesos de socialización temprana, además de acercarlos de modo preliminar a la producción de conocimiento y al desarrollo de sus potenciales humanos.

Como efecto de estas condiciones, el preescolar público bogotano, en específico, adoptó la forma de un lugar para el conocimiento en el que se preparaban a los niños y niñas para desenvolverse socialmente y para afrontar los retos de la educación primaria mediante la apropiación de unos contenidos curriculares previamente establecidos.

Dicho currículo centrado en las materias escolares se mantuvo durante la década de 1980 en el preescolar como un dispositivo de poder para orientar la enseñanza. Sin embargo, resultado de diversas prácticas singulares, de condiciones de emergencia particulares y de la irrupción e instalación de una nueva racionalidad educativa esta situación se trasfiguró, pues muchas de estas materias escolares comenzaron a desleírse de las prácticas de enseñanza en el preescolar, como, por ejemplo, la educación sexual o la educación religiosa. Del

3 Dicha racionalidad se enmarcaba por la presencia del Programa de Mejoramiento Cualitativo de la Educación, en el modo de la Tecnología Educativa, la irrupción de la Renovación Curricular que promovió programas de enseñanza predeterminados por niveles para la escuela, la introducción de la preescolarización como dispositivo de regulación de la infancia, entre otras condiciones. mismo modo, otras cambiaron su situación dentro del currículo, como la Educación Estética, la Educación Física, las Ciencias Naturales y Salud y las Ciencias Sociales, mientras que las demás se convirtieron en las asignaturas escolares a privilegiar de la enseñanza preescolar, como lo fueron la prelecto-escritura y la prematemática.

Con esta nueva retórica que prorrumpió no solo se inició el desvanecimiento de algunas asignaturas escolares y el mantenimiento de otras sino la exaltación de aquellas que se considerarán como los saberes escolares fundamentales y legítimamente reconocidos para garantizar la enseñanza preescolar, la producción e interés por el conocimiento y, por supuesto, la regulación de los niños y niñas, la garantía del éxito posterior en la escuela y el enfrentamiento de la deserción y el fracaso escolar.

Esta floreciente racionalidad educativa se instauró en la década de los 90 y determinó de un modo particular y distinto a los sistemas educativos en el mundo. Esta resaltó la importancia de impulsar políticas de protección y atención infantil para enfrentar los problemas educativos, nutricionales, de salud y de mortandad, reconociéndose con ello, que "la expansión de la escolaridad constituye una variable crucial en el éxito de cualquier proyecto de democratización de la enseñanza" (MEN, 1996, p. 22).

Aunado a ello, la preocupación por el aprendizaje en vez de la enseñanza, la introducción de las teorías constructivistas (que privilegiaban la actividad de los niños desvirtuando los contenidos de enseñanza y los currículos centrados en materias escolares), la inmersión del enfoque de la satisfacción de las necesidades básicas de aprendizaje, la comprensión del desarrollo humano como un asunto integral acoplado a una multiplicidad de dimensiones, el impulso de la idea de la educación como el factor esencial para lograr el desarrollo productivo y humano, entre otros aspectos, se convertían en los asuntos estratégicos que en específico comenzaron a cuestionar el carácter instrumental establecido de la escuela preescolar, conducente a la preparación y aprestamiento preliminar para la educación primaria.

Lo anterior, causó la enunciación de la importancia de instaurar una escuela preescolar distinta. Para el caso del país, se materializó en la creación 
del Grado Cero, una estrategia de intervención en el marco del Plan de Apertura Educativa del presidente César Gaviria (1991-1994) con la que se procuró, entre otras cosas, ofrecer a los niños y niñas entre los 5 y 6 años con oportunidades educativas relacionadas con el desarrollo de su personalidad, con su desarrollo, aprendizaje y con el favorecimiento de "una mejor apropiación de los contenidos y procesos de la educación básica primaria y, por ende, un mayor rendimiento en la misma" (MEN, 1996, p. 11).

En este marco, algunos de los saberes escolares, a modo de materias de enseñanza, comenzaron a diluirse de las prácticas de enseñanza de los maestros y maestras, pero otros se fueron fortaleciendo, manteniendo y privilegiando respecto a las demás asignaturas. En especial, aquellos que enseñaban esos contenidos que contribuían en el desarrollo humano integral y en la constitución de aquellos sujetos de carácter social, político y ético que para entonces se requerían.

Pero además de esto, se favoreció la inclusión de formas de curricularización que no solo se alejaron de esos contenidos preestablecidos y aislados instalados en los 80 sino que destacaron la acción y las actividades realizadas por los niños y niñas en el aula como los asuntos fundamentales a considerar, complementando las estrategias de regulación infantil emergentes y el apoyo a una enseñanza preescolar distinta.

\section{Los saberes escolares y la enseñanza}

Los saberes escolares, al ser invenciones históricas inscritas en la racionalidad de cada época que obedecen a sus reglas de operación, a las acciones sobre las acciones que se suscitan, a los juegos y estrategias de poder y a los modos particulares de ser del tiempo, no siempre han tenido la misma procedencia, forma, función y funcionamiento en un periodo determinado.

Según Chervel (1991), inicialmente se asociaron a aquello que se requería para lograr el desarrollo intelectual de los aprendices y para reprimir aqueIlas "conductas susceptibles de alterar el orden establecido" (p. 60). Sin embargo, dicha concepción se fue disolviendo en el tiempo de la escuela para asumir nuevas formas.
Cuando aparecen en la escuela no solo orientaron la constitución de subjetividades y su sentido de un modo distinto, sino que se emplearon para alimentar el espíritu, el intelecto, el crecimiento mental y personal, la sabiduría, la inteligencia y cultivar la cultura de los estudiantes que allí asistían. Por tal razón, no se intencionaron hacia la formación académica o la escolarización.

A partir del siglo XX, dicha concepción cambió para asumir el carácter de "regularidades institucionalizadas [...], en forma de asignaturas escolares" (Viñao, 2006, p. 248), de contenidos de trasmisión cultural que se usaban en la escuela para orientar la instrucción de los niños, niñas y jóvenes. Así, adquirieron el carácter de "conjunto específico de conocimientos que tiene sus características propias en el ámbito de la enseñanza, la formación, los mecanismos, los métodos y las materias" (Chervel, 1991, p. 60), acoplándose como estructuras rígidas de contenidos para la enseñanza.

Así pues, se reconoce que los saberes escolares no siempre han tenido la forma de una materia escolar o el mismo significado o propósito, ni mucho menos que han estado acoplados a la escolarización. Por eso, no se pueden comprender como "algo [...] dado sino construido, [...] [sino como] un producto social e histórico" (Viñao, 2006, p. 248), mutaciones que se materializan de múltiples maneras en el tiempo de la escuela, variando su estructura, su función y modo de operar, trascendiendo "[...] pensar los saberes y las disciplinas escolares como formas de apropiación de la ciencia y los saberes en la escuela" (Ríos, 2015, p. 11).

Esto significa que no siempre han tenido el carácter de aquello que se enseña y utiliza en los aprendizajes en la escuela o al conjunto de contenidos inscritos a un listado de asignaturas. Es más:

Con esto se busca mostrar que los saberes escolares y sus materializaciones a la manera de temas, materias y contenidos escolares, no solo poseen diversos significados sino una historia, una jerarquía frente a otros, una autonomía respecto a las disciplinas científicas y una estructura interna, unos lenguajes, unos dominios, unas metodologías y unas problemáticas que los caracteriza. (Cárdenas et al., 2018, p. 17) 
Basados en lo anterior, se entiende, además, que los saberes escolares no siempre han estado en la escuela en relación con el conocimiento sino que son el efecto de una manera particular de ser de la historia en la que se requirió otorgarle a la escuela un sentido académico acoplado a las estrategias de escolarización de la infancia y la juventud, al conocimiento y al academicismo. Por tanto, siguiendo a Ríos:

[...] para analizar y enunciar saberes y disciplinas escolares debemos trabajar más en función de las áreas de enseñanza, porque en la escuela funcionan y se enseñan saberes y disciplinas que no tienen nada que ver con la disciplina de referencia, ya que dependen del campo especifico de las prácticas y de los sujetos de la enseñanza. (2015, p. 12)

Los saberes escolares entonces, no son objetos consistentes, macizos y arraigados en la escuela sino metamorfismos, variaciones, alteraciones que actúan conformes a las reglas de funcionamiento de cada racionalidad, por tanto, "más allá de ser simples vulgarizaciones del conocimiento científi$\mathrm{CO}$, se institucionalizan como invenciones propias de la escuela, fluctuaciones, coyunturas de cada época, que dan cuenta del acontecer escolar, de sus tensiones, cultura, ideales sociales y escolares" (Cárdenas, 2016, p. 91), susceptibles de transfigurarse, de mutar y adoptar formas distintas para orientar la enseñanza, que así como aparecen legitimados en ciertos momentos, están dispuestos a desvanecerse, a desvirtuarse, a desaparecer para permitir que otros se instalen y orienten la enseñanza en la escuela, que permitieron "[...] la emergencia de la tierna edad y de los párvulos como subetapas de la infancia [...]" (Martínez, 2015, p. 1).

Es más, no son solamente prescripciones de orden curricular que obedecen a la voluntad o decisión de algún sujeto e institución gubernamental o político, a las directrices formuladas en los libros de textos, sino que se conforman en una "[...] una dimensión del saber pedagógico funciona como un flujo de relaciones con el afuera y el adentro de la escuela" (Ríos, 2015, p. 17). Son invenciones entonces, que pueden estar en la escuela o ser parte de ella, como lo señala Marín (2015), acopladas a las condiciones de cada época en las que requirió de los saberes escolares para regular a la infancia y la juventud y amoldarla a las exigencias del momento, complementando con ello, las estrategias de escolarización. Con lo que se reconoce el saber escolar como instancia que permite "[...] la reescritura de los discursos y prácticas, que permitieron la constitución de la enseñanza infantil como el primer nivel de instrucción y de la educación infantil como una práctica de saber" (Martínez, 2018, p. 290).

\section{Los saberes escolares en el preescolar} de la década de 1990

En los años 80 estaba establecida en el país una racionalidad educativa materializada en la Tecnología Instruccional y en la Renovación Curricular como estrategias para el mejoramiento educativo y la enseñanza en las escuelas y colegios públicos. En el preescolar ofrecido por el Estado se incorporó una serie de contenidos de enseñanza en la forma de materias escolares a través de las cuales se pretendió el desarrollo y la regulación infantil, el aprestamiento para la escuela primaria y la institución de este nivel educativo como instancia inicial para acercar a los niños y niñas entre los 5 y 6 años a la producción del conocimiento, afrontar la ineficiencia de la educación primaria, evitar el fracaso y la repitencia escolar.

No obstante, con el trascurrir del tiempo, estas formas de enseñanza se fueron desvaneciendo, cambiando su posición o ubicándose en un lugar privilegiado, para permitir la inclusión de maneras distintas de organizar y estructurar aquello que se les enseñaba en el preescolar, constituyendo al mismo tiempo, una manera particular de comprender la infancia preescolarizada como una subjetividad integral, con una multiplicidad de potenciales y dimensiones que se debían considerar en el proceso formativo, en prorrumpía en contradicción con la apuesta curricular que se gestaba.

Sin embargo, a comienzos de la década de los 90 estas condiciones se trasfiguraron. Una nueva racionalidad educativa se estableció no solo enunciando la importancia del desarrollo humano en la escuela, la articulación del sector educativo a los intereses del modelo económico, de la importancia de satisfacer las necesidades básicas de aprendizaje que se tradujeron en la enseñanza de la lectura, 
escritura y el cálculo entre otras, sino que el preescolar debía orientarse aunque no de manera selecta hacia "la construcción del conocimiento y [...] la trasmisión del saber sistematizado" (Organización Mundial de Educación Preescolar [OMEP], 1993, p. 56). Con ello, se proponía la creación de una institución de educación que no solo reconociera el desarrollo humano como un proceso integral y global constituido por los aspectos biológicos, cognoscitivos, psicomotrices, socio-afectivos y espirituales, sino que dirigiera su programa de trabajo, acciones y actividades pedagógicas y didácticas hacia su consecución. Además, se expuso que los contenidos educativos eran fundamentales en el preescolar ya que a través ellos se:

[...] transmiten el modelo de sociedad, de organización social, de distribución del espacio económico y social entre las clases, de posibilidades y de expectativas que uno puede alimentar para sí y para sus hijos. Si no transmite explícitamente, a través de los textos y ejemplos, lo hace por medio de formas indirectas como las actitudes, las exigencias, la organización de las clases, etc. Incorporados [...], dichos valores, actitudes, expectativas van a constituir la base del comportamiento futuro. (OMEP, 1993, p. 59)

Como consecuencia de estos modos de enunciación de la época, surgió la Ley General de Educación de 1991, la cual impulsó una manera distinta de enfocar el quehacer preescolar en el aula. El método fue el del trabajo por proyectos que se instauró como "una nueva propuesta curricular basada en los planteamientos de la pedagogía activa y los enfoques del constructivismo" (MEN, 1996c, p. 16), que consideraba los intereses y necesidades particulares de la infancia preescolar y la importancia del desarrollo de sus habilidades y la construcción de conocimiento "[...] a través de la búsqueda de soluciones a preguntas y problemas que surgen del entorno [...]" (p. 28).

Unido a esto, y en el marco del Plan de Apertura Educativa (1991-1994), se formuló la necesidad de establecer un preescolar que respondiera a estas exigencias, apoyado en el enfoque constructivista y en la pedagogía activa como orientaciones para enfrentar el modelo instruccional establecido en el preescolar.
Dicha estrategia se denominó Grado Cero, un nivel de transición entre el hogar y la escuela primaria, que en la forma de propuesta pedagógica obligatoria buscó enfrentar la ineficiencia de la educación primaria, el fracaso escolar, "la falta de aprestamiento [...] la carencia de elementos que posibiliten la transición al grado primero" (MEN, 1996c, p. 17) y contribuir en el aprendizaje formal y el conocimiento, sumando a esto el favorecer el desarrollo integral, de la autonomía y la socialización de los niños y niñas.

Gracias a estas narrativas se fortaleció la concepción del desarrollo de los niños y niñas como un proceso integral y global "constituido por una multiplicidad de dimensiones, entre las que se destacan las dimensiones corporal, cognitiva, comunicativa, ética, espiritual y estética, que debían considerarse al momento de la planificación curricular de los maestros" (Cárdenas y Cárdenas, 2016, p. 57), el cual era posible de potenciarse mediante el trabajo alrededor del desarrollo de las dimensiones y no necesariamente con el aprendizaje de contenidos educativos y curriculares preestablecidos, hecho que va a impulsar la trasfiguración de la enseñanza centrada en materias escolares, herencia de los años 80, para permitir la introducción de formas distintas para enseñar, con carácter articulado y respondiendo, precisamente, a esa concepción integral del desarrollo infantil que prorrumpía.

Así las cosas, las asignaturas académicas comenzaron a reconfigurarse, a cambiar su condición, función, funcionamiento, posición, forma y lugar, y por supuesto, el modo de ser de la enseñanza en el preescolar. Las Ciencias Naturales y Salud, la Educación Estética y las Ciencias Sociales, por ejemplo, enfrentaron un cambio en su posición dentro del plan de estudios, perdiendo algo de importancia respecto a las demás. Por su parte, la Prelectura, la Preescritura y las Prematemáticas cambiaron su estado para ubicarse como los saberes escolares a privilegiar y los fundamentales para abordar el trabajo educativo en el aula. La Educación Física y la Educación Religiosa, por otra parte, tendieron a desaparecer de la enseñanza en el preescolar.

A mediados de los años 90, el discurso sobre la educación preescolar como instancia preparatoria para la escuela primaria comenzó a desvanecerse 
para impulsar la enunciación de la educación preescolar como un proceso integral que debía considerar el desarrollo de las dimensiones humanas de manera integrada en la formación infantil. Con lo cual, las condiciones de la enseñanza cambiaron aún más, pues, esas dimensiones se fueron curricularizando ${ }^{4}$, es decir, tomando la forma de un contenido de enseñanza en el que se integraron diversos asuntos, temáticas y propósitos.

Este hecho se concretó en la Resolución 2343 de 1996, en la que se establecieron no solo los lineamientos generales de los procesos curriculares del servicio público educativo y los indicadores de logros curriculares para la educación formal sino en la que los contenidos de enseñanza (a modo de asignaturas escolares) y su intención de preescolarizar, de enseñar, de aprestar, de preparar para la primaria y trasmitir la cultura, se fue diluyendo para orientar la preocupación en el aula preescolar hacia el desarrollo de las dimensiones humanas (biológica, psicológica y social), los propósitos de

76 la enseñanza (más que a los contenidos), la satisfacción de sus necesidades básicas de aprendizaje y el bienestar de los niños y niñas.

En relación con ello, según Rubiano (como se cita en Cárdenas, 2014, p. 285), para ese entonces, en el preescolar público no se determinaron áreas específicas de conocimiento en forma separada. Por el contrario, se propuso trabajar de manera integrada dichas áreas, incluso los temas de enseñanza obligatoria, a través de diferentes estrategias metodológicas como el trabajo por proyectos pedagógicos.

Es por esto que la intención de formular un plan de estudios para el preescolar se fue disipando declarando que "simplemente, las actividades integradas desarrolladas en el proyecto pedagógico serán consideradas como el Plan de Estudios" (Cárdenas, 2014, p. 285).

De este modo, los proyectos pedagógicos (al igual que el juego) se convirtieron en la estrategia didáctica para el preescolar mediante la cual no solo se pretendió el desarrollo integral de los niños y niñas, sino que se mostró con ello al conocimiento como una estructura global además de articular los

4 Respecto a este tema se puede profundizar en el documento de Cárdenas y Cárdenas (2016). contenidos de las materias escolares a las dimensiones humanas (biológica, psicológica y social).

En este marco, los proyectos pedagógicos se concibieron como "un proceso de construcción colectiva y permanente de relaciones, conocimientos y habilidades que se va estructurando a través de la búsqueda de soluciones a preguntas y problemas que surgen del entorno y la cultura del cual el grupo y el maestro hacen parte" (MEN, 1996, p. 61), en los que los contenidos de las materias de enseñanza, en la forma de temáticas de conocimiento, se asociaron a problemas de interés formulados con base en las vivencias de los preescolares. Los saberes escolares, entonces, sirvieron de complemento para el aprendizaje infantil y el desarrollo integral más que el fin último de los procesos de formación en el preescolar.

En conjunto con esto, se comenzó a enunciar que lo importante en la formación de los niños y niñas, entre otras cosas, era "la adquisición de los elementos de la lengua materna y la aproximación constructiva a la lengua escrita y a las relaciones lógicas de los conceptos matemáticos" (MEN, 1996, p. 29), otorgándole un valor fundamental a los saberes escolares relacionados con la lengua escrita y el conocimiento matemático por encima de los otros establecidos, y con ello, resaltando la importancia del alcance de los propósitos y de las actividades de enseñanza sobre el aprendizaje de los contenidos curriculares.

Ante la ausencia explícita de los contenidos para la enseñanza, sus lineamientos y la poca claridad respecto a qué enseñar en el preescolar en los discursos de la época, las maestras recurrieron a inferir, deducir y extraer de lo dispuesto, esos contenidos que se debían enseñar y articularlos con cada una de las dimensiones del desarrollo humano.

Así, de lo expuesto como propósitos para la dimensión corporal extrajeron como contenidos para la enseñanza las partes del cuerpo, la familia, la naturaleza y los hábitos de aseo, orden y presentación; de la dimensión comunicativa, la enseñanza de los textos narrativos y los medios de comunicación, así como una potente preocupación por enseñar las vocales y ciertas sílabas como ma, me, mi, mo, mu (a través de planas, rondas y la memorización de canciones y poemas), como fundamentos del proceso de la escritura y la lectura. 
De la dimensión cognitiva se resaltó la enseñanza de la noción de número, las nociones espaciales y las figuras geométricas básicas (cuadrado, triángulo, rectángulo y círculo), así como también el conteo y el acercamiento a la adición y la sustracción. En relación con la dimensión ética, actitudes y valores, se planteó la enseñanza de los valores relacionados con la resolución de conflictos y las normas de convivencia como el respeto, la responsabilidad, el compromiso, la puntualidad, entre otros. Y, finalmente, de la dimensión estética la enseñanza de los colores (a través de la pintura, del dibujo y del decorado de imágenes), las fiestas y las tradiciones culturales.

Pero también asociaron esas dimensiones de desarrollo infantil a las materias de enseñanza, de tal modo que con la dimensión cognitiva relacionaron las Prematemáticas y las Ciencias Naturales, con la dimensión comunicativa la Prelecto-escritura, con la dimensión corporal la educación física, con la dimensión ética, actitudes y valores las Ciencias Sociales y la Religión y con la dimensión estética la Educación Estética, constituyendo cada una de estas dimensiones en un contenido de aprendizaje posible de ser enseñando mediante el juego, un proyecto pedagógico o una unidad didáctica.

Así, los contenidos de las asignaturas académicas se amalgamaron con las dimensiones humanas, adoptando un nuevo ropaje que orientó en aquel momento la enseñanza, con lo que no solo se inició el proceso de dilución de las materias de enseñanza en el preescolar, sino que se fue desdibujando la intención de este nivel educativo como un estado preparatorio para el ingreso a la escuela primaria.

\section{Resultados iniciales}

Con base en las exploraciones realizadas, y conforme con los expedientes documentales de la época, se puede de manera preliminar resaltar que durante la primera mitad del decenio de 1990 la racionalidad educativa instalada en el país impulsó la creación del Grado Cero como una instancia inicial del sistema educativo a través del cual se pretendió, entre otras cosas, el aprestamiento de los niños y niñas para afrontar las tareas y retos de la educación primaria.
De esta manera, se formuló como una estrategia complementaria para apoyar la regulación, el gobierno y la formación infantil, la inclusión de una serie de saberes escolares, en la forma de materias de enseñanza, que se instauraron como dispositivos de subjetivación infantil, fundamentalmente el conocimiento matemático, el cual se sustentó en el propósito de contribuir al "desarrollo del pensamiento para que el niño llegue a la comprensión de los conceptos que le enseñan como consecuencia de su capacidad para establecer las relaciones lógicas implicadas en ellos" (MEN, 1996a, p. 27), y en la enseñanza de contenidos relacionados con el manejo del número como sistema, conteo, relaciones de orden, relaciones de equivalencia, clasificaciones, manejo de operaciones aditivas, resolución de problemas de cuantificación, nociones de espacio y tiempo, entre otros, fundados en experiencias significativas proporcionadas por los maestros y maestras, muchos de los cuales se mantuvieron en los años 90, herencia de la década anterior, y en principios como la globalidad, integralidad, lúdica, reconocimiento de la diferencia y construcción social de conocimiento.

Y la enseñanza de la lengua escrita que, apoyada en la perspectiva constructivista, le apostó por la introducción de situaciones significativas por parte de los maestros y maestras mediante la enseñanza de contenidos relacionados con la "expresión, producción y circulación, contacto y contrastación de textos escritos" (MEN, 1996b, p. 38).

Adicional a esto, con este tipo de trabajos se aporta en la descripción y análisis de los saberes escolares en el preescolar, un territorio emergente de exploración pedagógica, educativa e histórica. Pero, además, un aporte al reconocimiento de la condición mutable de los saberes escolares, objetivaciones que fluyen efecto de la conjunción de múltiples condiciones que determinan la enseñanza y el carácter de la escuela preescolar.

\section{Conclusiones preliminares}

En los últimos años, el estudio de los saberes escolares se ha venido constituyendo en un campo reciente de exploración histórica, educativa y pedagógica. A pesar de esto, la historia de las disciplinas y saberes escolares en el preescolar se 
constituye en un asunto de reflexión floreciente, un territorio por navegar, indagar y construir, en el que algunos estudios le han venido apostado por problematizar la pregunta por el qué enseñar en este nivel educativo, colocando en un estatus distinto el análisis por los saberes escolares y ubicándolo como un asunto de interés de las agendas, de los debates y de la formulación de políticas educativas para el preescolar, en particular, para el ofrecido por el Estado.

Como se observó, en el preescolar público bogotano (y por supuesto en Colombia), los saberes escolares, en el modo de asignaturas asociadas a las áreas del conocimiento, son una invención reciente, formas de subjetivación y gobierno infantil, incluidos en la década de los 80 cuando el preescolar público floreció y se mantuvo para orientar la enseñanza. Sin embargo, efecto de diversas condiciones, se fueron diluyendo para dispersarse en las prácticas de enseñanza, favoreciendo la incursión de otros modos de ser de los contenidos utilizados para enseñar y escolarizar, que así, como en cierto instante se articularon a las áreas de conocimiento, son susceptibles de desvanecerse, mutar, reconfigurarse o mantenerse. Por ello, hoy muchas de estas materias escolares se han venido diluyendo, y hay otras que están adquiriendo nuevas formas y estatus para orientar la enseñanza en el preescolar. Por lo que surge con ello la necesidad de sospechar esta condición, su esencia y cuestionar también las concepciones, sentidos y orientaciones que en el presente asume el preescolar y aquello que se le debe enseñar a los niños y niñas en lo local, distrital y nacional.

\section{Referencias}

Álvarez, A. y Taborda, A. (2014). La historia de los saberes escolares: nuevas miradas a la historia y la educación en América Latina. En N. Arata y M. Southwell (comps.), Ideas en la educación Latinoamericana. Un balance historiográfico (pp. 163-180). Buenos Aires: Unipe, Editorial Universitaria. DOI: https://doi. org/10.17227/01212494.42pys21.29

Álvarez, A. (2015). Del saber pedagógico a los saberes escolares. Pedagogías y saberes, 42, 21-29.
Cárdenas, O. L. (2014). La pre-escolarización del niño en la escuela pública colombiana (1960-1990). Ibagué, Colombia: Universidad del Tolima.

Cárdenas, M. y Cárdenas, O. (2016). El trabajo por dimensiones en el preescolar: sospecha por la naturalización de un discurso. Educación y Pedagogía: aportes de maestros y maestras de Bogotá. Serie Investigación IDEP. Bogotá: Alcaldía Mayor de Bogotá; Instituto para la Investigación Educativa y el Desarrollo Pedagógico, IDEP. Recuperado de http://www.idep.edu.co/sites/ default/files/libros/Educacion_pedagogia_Aportes_de_maestros.pdf https://doi.org/10.14483/ udistrital.jour.infimg.2016.1.a06

Cárdenas, O. L. (2016). Historia de los saberes escolares en el preescolar público bogotano. Infancias Imágenes, 15(1), 89-102. Recuperado de https://revistas.udistrital.edu.co/ojs/index. php/infancias/article/view/9578/11416

Cárdenas, O. L.; Aguilera, Y.; Beltrán, V.; Calderón, N.; Camargo, L.; Castillo, L.; Díaz, G.; Lasso, O.; Martínez, D.; Pérez, L.; Siabato, L.; Silva, P.; Suárez, J. y Ubaque, A. (2018). La historia de los saberes en el preescolar de la escuela pública bogotana (1980-1990). Ibagué, Colombia: Universidad del Tolima.

Chervel, A. (1991). Historia de las disciplinas escolares. Reflexiones sobre un campo de investigación. Revista de Educación, 295, 39-59. Recuperado de http://www.mecd.gob.es/dctm/ revista-de-educacion/numeros\%20completos/ re295.pdf?documentld=0901 e72 b8130f412

Cuesta, R. (1997). Sociogénesis de una disciplina escolar: la historia. Barcelona: Pomares-Corredor. Deleuze, G. (1987). Foucault. Barcelona: Paidós.

Foucault, M. (1983). Nietzsche, la genealogía, la historia. Sociología 5. Facultad de Sociología de Unaula. Recuperado de http://www.pensament.cat/filoxarxa/filoxarxa/pdf/Michel\%20Foucault\%20-\%20 Nietzschegenealogiahistoria.pdf

Goodson, I. (1991, mayo-agosto). La construcción social del curriculum. Posibilidades y ámbitos de investigación de la historia del curriculum. Revista de Educación, 295, 7-39. Recuperado de http://www.mecd.gob.es/dctm/ revista-de-educacion/numeros\%20completos/ re295.pdf?documentld=0901 e72 b8130f412 
Martínez Velasco, M. Á. (2015). De las escuelas primarias a las escuelas infantiles: la configuración de un saber escolar para la educación de la tierna edad y de los párvulos en Colombia, 1870- 1930. Universidad de Antioquia, Facultad de Educación, Departamento de Educación Avanzada. Recuperado de https:// www.researchgate.net/profile/Miguel_Martinez_Velasco/publication/322448370_De_ las_escuelas_primarias_a_las_escuelas_infantiles_la_configuracion_de_un_saber_escolar_para_la_educacion_de_la_tierna_edad_y_ de_los_parvulos_en_Colombia_1870-1930/ links/5a59549d0f7e9b5fb38405e7/

De-las-escuelas-primarias-a-las-escuelas-infantiles-la-configuracion-de-un-saber-escolar-para-la-educacion-de-la-tierna-edad-yde-los-parvulos-en-Colombia-1870-1930.pdf

Martínez Velasco, M. (2018). Educación infantil y oficio de maestra-jardinera, Medellín-Colombia: 1915-1930. Historia y Memoria, 16, 281-318. Recuperado de https://revistas.uptc. edu.co/index.php/historia_memoria/article/ view/7193 https://doi.org/10.19053/20275137. n16.2018.7193

Marín, D. L. (2015). Una cartografía sobre los saberes escolares. En Saberes, escuela y ciudad. Una mirada a los proyectos de maestros y maestras del Distrito Capital (pp. 13-38). Bogotá: Instituto para la Investigación Educativa y el Desarrollo Pedagógico, IDEP.

Ministerio de Educación Nacional de la República de Colombia (1996a). Propuesta curricular para el grado cero: marcos político, conceptual y pedagógico. Serie Documentos de Trabajo. Bogotá.
Ministerio de Educación Nacional de la República de Colombia (1996b). El conocimiento matemático en el grado cero. Serie documentos de trabajo. Bogotá: MEN.

Ministerio de Educación Nacional de la República de Colombia (1996c). La construcción de la lengua escrita en el grado cero. Serie documentos de trabajo. Bogotá: MEN.

Ministerio de Educación Nacional de la República de Colombia (1996d). Hacia la comprensión del nivel de educación preescolar desde el espíritu de la Ley General de Educación. Bogotá: MEN.

Ministerio de Educación Nacional, Colombia (1996e). Resolución 2343. Bogotá.

Organización Mundial de Educación Preescolar (OMEP) (1993). Alternativas de atención a la primera infancia: en la familia, en la escuela y en la comunidad. Memorias del VII Congreso Nacional de Educación Preescolar 45. Julio 5-9, Bogotá: Unesco. Recuperado de https://unesdoc.unesco.org/ark:/48223/pf0000112009

Ríos, R. (2105). Historia de la enseñanza en Colombia: entre saberes y disciplinas escolares. Pedagogía y Saberes, 42, 9-20.

Viñao, A. (2006). La historia de las disciplinas escolares. Historia de la Educación, 25, 243-269. Recuperado de http://rca.usal.es/ revistas_trabajo/index.php/0212-0267/article/ view/11181/11603

Zuluaga, O. L. (2003). Foucault: una lectura desde la práctica pedagógica. En: Foucault, la pedagogía y la educación. Pensar de otro modo. Colección Pedagogía e Historia. Bogotá: Cooperativa Editorial Magisterio. 